\title{
Study of the lipid-lowering action of choloxin and Nilevar in patients with chronic renal failure
}

\author{
E. N. WARDLE \\ M.A., M.B., M.R.C.P. \\ W. SCHARDT \\ B.A. \\ P. R. ULDALL \\ M.D., M.R.C.P.
Ann Brown, Dorcas Jonfiah, Audrey Moore, Rosemary Park, Elizabeth Wood
Dieticians

Newcastle General Hospital

\begin{abstract}
Summary
Lowering of lipids in patients with chronic renal failure is advantageous but cannot be done by calorie restriction. In a controlled study the anabolic steroid norethandrolone (Nilevar) was found to lower triglycerides by $50 \%$, while D-thyroxine (Choloxin) lowered the cholesterol by $25 \%$. Both drugs increased the activity of lipoprotein lipase in spite of uraemic inhibition. Norethandrolone also reduced basal serum insulin levels. Norethandrolone seems appropriate for underweight patients and D-thyroxine for overweight patients, but side effects are more frequent than in nonuraemic patients.
\end{abstract}

\section{Introduction}

Patients with chronic renal failure tend to have high levels of serum triglyceride (Bagdade, 1970) and sometimes of cholesterol (Bagdade, Porte and Bierman, 1968; Brøns, Christensen and Horder, 1972). Increased triglyceride may depend in part on increased synthesis on account of the hyperinsulinism of chronic renal failure (Spitz et al., 1970) (Bierman, 1970), in part on an increased contribution of carbohydrate to their total calorie intake (Gutman et al., 1973), and in part on uraemic inhibition of the enzyme lipoprotein lipase (Boyer and Scheig, 1970). Figure 1 is designed to explain these relationships. Now the implication is that chronic renal failure patients might be at risk from accelerated development of atherosclerosis because of their hyperlipaemia, which is incidentally not corrected by dialysis (Bagdade et al., 1968; Roodvoets et al., 1967). Accelerated atherosclerosis is a feature of nephrotic patients (Berlyne and Mallick, 1969). Lipaemia in chronic renal failure patients assumes

Correspondence: Dr E. N. Wardle, Department of Medicine, Royal Victoria Infirmary, Newcastle upon Tyne, NE1 4LP. importance when life is to be prolonged by dialysis with a view to renal transplantation. Rotter and Roettger (1973) have reported that coronary insufficiency, as judged by myocardial scars, is certainly increased in dialysis patients.

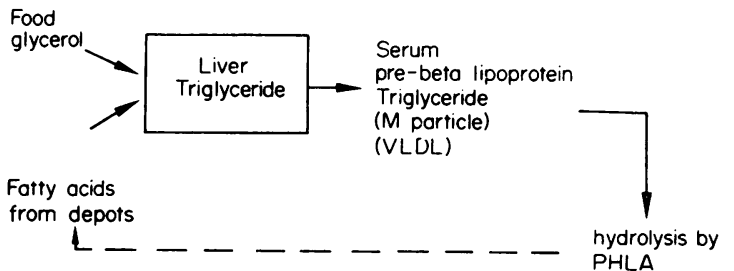

FIG. 1. Metabolic diagram showing how liver synthesis of plasma triglyceride is derived on the one hand from carbohydrate of the food and on the other from fatty acids mobilized from the fat depots.

The effects of therapeutic agents on lipid metabolism in chronic renal failure patients are largely unexplored. There is some impression that agents might not be effective (David et al., 1972). In other hyperlipidaemic patients D-thyroxine (Choloxin) is known to lower the cholesterol (Schneeberg et al., 1962; Hollister and Arans, 1962). Triglyceride levels are often lowered by androgens (Furman et al., 1968), which may more conveniently be given as anabolic steroids, among which the agent oxandrolone (hydroxy-methyl-oxa-androstanone) is known to reduce carbohydrate induced hypertriglyceridaemia (Sachs and Wolfman, 1968).

We have conducted a study of lipids in the serum of non-nephrotic chronic renal failure patients to examine first the effect of the anabolic steroid, norethandrolone (Nilevar) and then the actions of the cholesterol-lowering agent D-thyroxine (Choloxin). 


\section{Method}

Fifteen patients selected for the stability of their non-nephrotic chronic renal failure volunteered to participate in the trial. Five had chronic pyelonephritis, three polycystic kidneys, three chronic glomerulonephritis and four chronic renal failure of unknown origin with hypertension. Only three patients had a urinary protein excretion exceeding $1 \mathrm{~g} / 24 \mathrm{hr}$. The mean serum creatinine level was 4.6 $\mathrm{mg} \%$ and creatinine clearances were in the range 5-60 $\mathrm{ml} / \mathrm{min}$, with a mean of $22 \mathrm{ml} / \mathrm{min}$. At fortnightly intervals they attended after an overnight fast and had blood taken for serum triglycerides (Biochemical combination glycerokinase technique) and serum cholesterol (Modified Technicon N12), and additionally, serum free fatty acids (Duncombe, 1964) and serum post-heparin lipoprotein lipase activity (PHLA) by the method of Muir (1967), after heparin $0 \cdot 1 \mathrm{mg} / \mathrm{kg}$ given intravenously. Basal fasting plasma insulin levels were also measured using the Lepetit Insulin kit, which is a double antibody charcoal adsorption immunoassay. On one day each week using weighing scales they filled in a standard dietary questionnaire so that for that representative day their consumption of protein, fat and carbohydrate and, hence, their total calorie intake, could be ascertained. At each visit they were weighed and their skin-fold subcutaneous fat thickness was measured with calipers.

After a control period of 6 weeks, all patients started to take norethandrolone $20 \mathrm{mg} /$ day and this was continued for 10 weeks, after which they entered another control period of 6 weeks. Thereafter under blind conditions they received either placebo or D-thyroxine at increasing dosage over a period of three weeks to $2 \mathrm{mg}$ thrice daily, which was then maintained for another 7 weeks. In retrospect it turned out that eight patients received Choloxin and seven placebo. Finally, there was another control period of 4 weeks. At each visit there was a full examination and biochemical assessment.

\section{Results and comment}

Table 1 gives a synopsis of the results of the changes in lipid parameters and dietary intake when on the two forms of treatment. Figure 2 depicts the course of events in one patient and illustrates the design of the trial. During the norethandrolone administration there was a progressive fall of triglyceride and it is of interest that this fall continued for 6 weeks after cessation, i.e. during the following control weeks (designated second control period). This curious finding means that the norethandrolone effect on the liver in these chronic renal failure patients persisted for at least 6 weeks after cessation of therapy. Although the study commenced in the winter months and finished in late summer, it is unlikely that a seasonal influence accounted for the low triglyceride levels in the second control period, because in the seven patients, who thereafter received placebo tablets, triglyceride levels did rise again.

When the patients on D-thyroxine are compared with those on placebo, it is evident that this drug caused the anticipated fall of serum cholesterol, and also that the rebound increase of triglyceride at the end of the norethandrolone period was considerably less in those patients who were on D-thyroxine. Further study of Table 1 shows that post-heparin lipoprotein lipase activity was increased during norethandrolone and $\mathrm{D}$-thyroxine therapy. This latter result explains in part the fall of serum triglyceride that was observed.

Norethandrolone was responsible for some side effects. Five of the fifteen patients complained of tiredness, and fluid retention with weight gain. A rise of blood pressure occurred in four. Indeed, one patient had to have peritoneal dialysis to remove excess fluid and therapy was withdrawn.

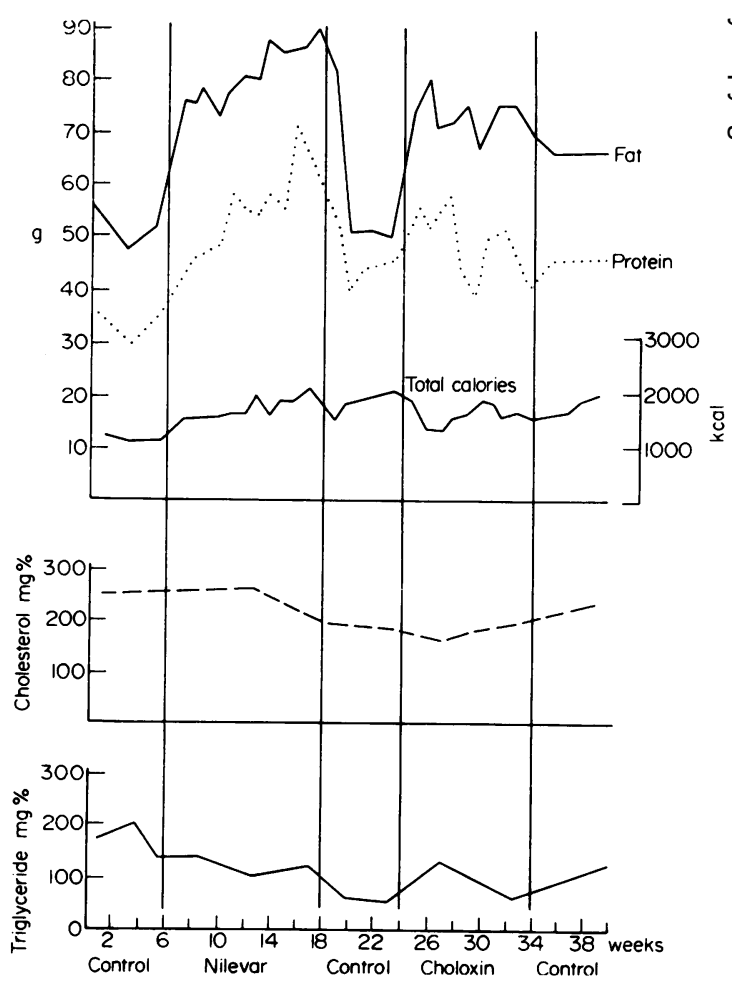

FIG. 2. This illustrates the plan of the study and shows the effects of Nilevar and Choloxin on dietary intake of protein, fat and total calories and on the levels of serum cholesterol and triglycerides. 
TABLE 1. Sequential changes induced by norethandrolone and D-thyroxine in fifteen patients

\begin{tabular}{|c|c|c|c|c|c|c|}
\hline & \multirow{2}{*}{$\begin{array}{c}\text { Basal } \\
\text { values } \\
(15)\end{array}$} & \multirow{2}{*}{$\begin{array}{l}10 \text { weeks } \\
\text { Nilevar } \\
\text { therapy (15) }\end{array}$} & \multirow{2}{*}{$\begin{array}{c}6 \text { weeks } \\
\text { second control } \\
\text { period (15) }\end{array}$} & \multicolumn{3}{|c|}{10 weeks } \\
\hline & & & & D-thyroxine (8) & or & Placebo (7) \\
\hline Cholesterol $\mathrm{mg} \%$ & $252 \pm 69$ & $236 \pm 86$ & $219 \pm 68$ & $\begin{array}{l}194 \pm 25 \\
P<0.01\end{array}$ & & $248 \pm 42$ \\
\hline Triglyceride $\mathbf{m g} \%$ & $252 \pm 93$ & $169 \pm 75$ & $\begin{array}{l}111 \pm 58 \\
P<0.001\end{array}$ & $\begin{array}{l}126 \pm 41 \\
P<0.001\end{array}$ & & $222 \pm 42$ \\
\hline FFA $\mu \mathrm{E} / \mathbf{1}$ & $430 \pm 60$ & $471 \pm 96$ & $440 \pm 80$ & $492 \pm 125$ & & $410 \pm 115$ \\
\hline PHLA $\mu \mathrm{E} / \mathrm{ml} / \mathrm{min}$ & $0 \cdot 2 \pm 0 \cdot 1$ & $\begin{array}{l}0.32 \pm 0.1 \\
P<0.005\end{array}$ & $0 \cdot 27 \pm 0 \cdot 12$ & $\begin{array}{c}0.30 \pm 0.05 \\
P<0.025\end{array}$ & & $0 \cdot 18 \pm 0 \cdot 1$ \\
\hline $\begin{array}{l}\text { Calories } \\
\text { consumed per day } \\
\text { Fat intake (g) } \\
\text { Protein intake (g) }\end{array}$ & $\begin{array}{c}1647 \pm 113 \\
71 \pm 7 \\
51 \pm 6\end{array}$ & $\begin{array}{c}1718 \pm 418 \\
77 \pm 18 \\
52 \pm 15\end{array}$ & $\begin{array}{c}1518 \pm 272 \\
68 \pm 17 \\
48 \pm 14\end{array}$ & $\begin{array}{c}1778 \pm 120 \\
73 \pm 10 \\
54 \pm 8\end{array}$ & & $\begin{array}{c}1678 \pm 98 \\
74 \pm 8 \\
50 \pm 9\end{array}$ \\
\hline Serum insulin $\mu \mathrm{U} / \mathrm{ml}$ & $7 \cdot 4 \pm 4 \cdot 0$ & $\begin{array}{l}2 \cdot 8 \pm 1 \cdot 7 \\
P<0 \cdot 001\end{array}$ & $5 \pm 2 \pm 4 \cdot 0$ & $5 \cdot 6 \pm 2 \cdot 6$ & & $5 \cdot 3 \pm 2 \cdot 7$ \\
\hline
\end{tabular}

\section{Discussion}

The triglyceride-lowering effect of clofibrate is now well known, although the mode of action is open to various interpretations (Sodhi, Kudchodkar and Horlick, 1971). The fall of the triglyceride-rich VLDL that it produces can be accompanied by some rise of the cholesterol-rich LDL (Miettinen, Penttilä and Lampainen, 1972). Clofibrate has been used in nephrotic patients but it is recommended that in uraemia blood levels should be estimated as side effects are easily produced. Many androgenicanabolic steroids lower chylomicrons, $\alpha$-lipoproteins and pre- $\beta$ lipoprotein triglycerides in, for example, patients with types III, IV and V hyperlipoproteinaemia. The best known are norethindrone acetate (Sigler and Issekutz, 1967) and oxandralone (Sachs and Wolfman, 1968). Oxandralone also has a liability to raise the levels of LDL (Sachs, Danielson and Weston, 1956; Glueck, 1971), and all these compounds alter serum proteins so that there is an elevation of protein-bound carbohydrate (Sachs et al., 1956) in the $\alpha$ and $\beta$ globulins.

Our results show that norethandrolone has a triglyceride-lowering effect in uraemic patients that is appreciable. An effect on the liver synthesis of lipoproteins has to be assumed. Solyom (1972) has recently suggested that the androgens reduce the synthesis of the apoprotein moiety of the lipoprotein molecule. However, in addition we have noted that norethandrolone increases the activity of PHLA, even in uraemic patients in whom serum inhibitors of PHLA are known to occur (Boyer and Sheig, 1970). Indeed it is already known that oxandralone and norethindrone acetate increase PHLA activity (Glueck, Swanson and Hutsell, 1970; Faergeman and Damgaard-Pedersen, 1973). Its use in uraemic patients can therefore be recommended for its triglyceride-lowering effect, but clearly attention must be paid to the possible side effects and the possibility of a cumulative action, as was apparent in these patients by the continued action for at least 4 weeks after withdrawal. It seems that the biological halflife of the drug is longer than circulating blood levels and so thereapeutic effect is not related to dosage. Further study may well show that a $10 \mathrm{mg}$ dose would be sufficient in chronic renal patients.

D-Thyroxine was found in uraemic patients to lower the cholesterol, and the triglyceride. It also produced weight loss, and this was certainly beneficial for overweight patients. In fact our patients did not receive propranolol concurrent with Choloxin but this is recommended in patients who are liable to latent ischaemic heart disease (Krikler, Lefevre and Lewis, 1971). The action of D-thyroxine is thought to be due to an increased catabolism of cholesterol to bile acids that are then lost in the faeces (Best and Duncan, 1960; Miettinen, 1968). In our patients it also increased PHLA activity: this is a new finding. Indeed a reduction of PHLA has been found in thyrotoxicosis and this is explained by an increased turnover of the enzyme (Tulloch, Lewis and Russell Fraser, 1973).

The observation that norethandrolone lowered basal insulin levels is important: studies are now required to see whether glucose-stimulated insulin secretion is also lowered by this drug. The finding must be compared with the recent report that clofibrate can restore normal triglyceride-insulin relations (Eaton and Nye, 1973). Lowering of insulin secretion by diazoxide results in reduction of serum triglyceride levels (Eaton and Nye, 1973).

In conclusion it appears that elevated triglyceride 
and cholesterol should be lowered in chronic renal failure patients. Such patients need, however, to maintain a high calorie intake on account of their protein restriction. Drug therapy is therefore required. Both norethandrolone and $\mathrm{D}$-thyroxine are effective, but the incidence of side effects with norethandrolone or D-thyroxine is greater than in non-uraemic patients. Both norethandrolone and D-thyroxine have been found to increase postheparin lipoprotein lipase activity, and this must be part explanation of the lowering of serum triglycerides. The finding that norethandrolone lowered basal insulin may also be relevant. We would recommend norethandrolone for underweight patients, but Dthyroxine for those who are overweight.

\section{Acknowledgments}

We are grateful to $\mathrm{Dr} \mathrm{A}$. Cassells-Smith and $\mathrm{Mr} \mathrm{G}$. Pendleton for the facilities of the lipid analysis techniques. The Nilevar was kindly supplied by Searle and the Choloxin and placebo tablets by Baxter Laboratories.

\section{References}

Bagdade, J. (1970) Uraemic lipaemia. Archives of Internal Medicine, 126, 875.

Bagdade, J.D., Porte, D. \& Bierman, E.L. (1968) Hypertriglyceridaemia: a metabolic consequence of chronic renal failure. New England Journal of Medicine, 279, 181.

Berlyne, G.M. \& Mallick, N.P. (1969) Ischaemic heart disease as a complication of nephrotic syndrome. Lancet, $\mathbf{i i}$, 399.

Best, M.M. \& Duncan, C.H. (1960) Effect of certain thyroxine analogues on liver cholesterol. American Journal of Physiology, 199, 1000.

BIERMAN, E.L. (1970) Abnormalities of carbohydrate and lipid metabolism in uraemia. Archives of Internal Medicine, 126, 790.

BOYER, J.L. \& SCHEIG, R.L. (1970) Inhibition of post-heparin lipolytic activity in uraemia and its relationship to hypertriglyceridaemia. Proceedings of the Society for Experimental Biology and Medicine, 134, 603.

Brøns, M., Christensen, M.C. \& Horder, M. (1972) Hyperlipoproteinaemia in patients with chronic renal failure. Acta medica scandinavica, 192, 119.

David, D.S., Hochgelernt, E., Rubin, A.L. \& Stenzel, K.H. (1972) Dietary management in renal failure. Lancet, ii, 34 .

Duncombe, W.G. (1964) Colorimetric microdetermination of non-esterified fatty acids in plasma. Clinica chimica acta, 9, 122.

EATON, R.P. \& NYE, W.H.R. (1973) The relationship between insulin secretion and triglyceride concentration in endogenous lipaemia. Journal of Laboratory and Clinical Medicine, 81, 682.

Faergeman, O. \& DamgaArd-Pedersen, F. (1973) Increase of post-heparin lipase activity by Oxandralone in familial hyperchylomicronaemia. Scandinavian Journal of Clinical and Laboratory Investigation, 31, 27.
Furman, R.H., Alavpovic, P., Bradford, R.H. \& Howard, R.P. (1968) Gonadal hormones, blood lipids and ischaemic heart disease. Progress in Biochemical Pharmacology, 4, 334.

GLUECK, C.H. (1971) Effect of oxandralone on plasma triglycerides and post-heparin lipolytic activity. Metabolism, 20, 691 .

Glueck, C.H., Swanson, F. \& Hutsell, T. (1970) Effect of oxandralone and norethindrone acetate on tissue and plasma lipases and triglycerides. Circulation, 42, 158.

Gutman, R.A., UY, A., Shalhoub, R.J., Wade, A.D., O'Connell, J.M.B. \& ReCANT, L. (1973) Hypertriglyceridaemia in chronic non-nephrotic renal failure. American Journal of Clinical Nutrition, 26, 165.

Hollister, L.E. \& ARANS, W.L. (1962) Effect of dextroisomers of thyroid hormones on serum cholesterol levels. Annals of Internal Medicine, 56, 570.

Krikler, D.M., LefeVre, D. \& Lewis, B. (1971) Dextrothyroxinc with propranolol in treatment of hypercholesterinaemia. Lancet, i, 934.

Miettinen, T.A. (1968) Mechanism of serum cholesterol reduction by thyroid hormones in hypothyroidism. Journal of Laboratory and Clinical Medicine, 71, 537.

Miettinen, T.A., PentTilä, I.M. \& Lampainen, E. (1972) Change of lipoprotein pattern by Clofibrate in hyperglyceridaemia and mixed hyperlipidaemia. Acta medica scandinavica, 192, 177.

MuIR, J.R. (1967) A rapid method for the assay of lipoprotein lipase. Clinica chimica acta, 17, 312.

Roodvoets, A.P., voN NeERBos, B.R., HoOgHWINKeL, G.J.M., Hulsmans, H.A.M. \& Beukers, H. (1967) Hyperlipaemia in patients on regular dialysis treatment. Proceedings of the European Dialysis and Transplant Association, 4, 257.

RotTer, W. \& Roettger, P. (1973) Comparative pathologicanatomic study of cases of chronic global renal insufficiency with and without preceding haemodialysis. Clinical Nephrology, 1, 257.

Sachs, B.A., DANielson, E. \& Weston, R.E. (1956) Effects of a synthetic anabolic steroid on serum proteins, lipoproteins and lipids. Journal of Clinical Endocrinology, 16, 1388.

SACHS, B.A. \& Wolfman, L. (1968) Effect of oxandralone on plasma lipids and lipoproteins of patients with disorders of lipid metabolism. Metabolism, 17, 400.

Schneeberg, N.G., Herman, E., Menduke, H. \& AltSCHULER, N.K. (1962) Reduction of serum cholesterol by sodium dextro-thyroxine in euthyroid subjects. Annals of Internal Medicine, 56, 265.

SigleR, M.H. \& IsSEKutz, B. (1967) Effects of anabolic steroids in chronic renal failure. Archives of Internal Medicine, 120, 408.

SodHI, H.S., KudchodkaR, B.J. \& Horlick, L. (1971) Effect of chlorophenoxyisobutyrate on the metabolism of endogenous glycerides in man. Metabolism, 20, 309.

Solyom, A. (1972) Effect of androgens on serum lipids and lipoproteins. Lipids, 7, 100.

Spitz, I.M., Rubenstein, A.H., Bersohn, I., Abrahams, C. \& LowY, C. (1970) Carbohydrate metabolism in renal disease. Quarterly Journal of Medicine, 39, N.S., 201.

Tulloch, B.R., Lewis, B. \& RusSell Fraser, T. (1973) Triglyceride metabolism in thyroid disease. Lancet. i, 391. 